\title{
Hormonal factors associated with hypogonadismand infertility in males - chromosomal abnormality
}

\author{
Lalitha.c ${ }^{1}$, Sayee.R, ${ }^{2}$ Jeyanthi. $\mathrm{K}^{1}$, Shubha. $\mathrm{R}^{1}$ \\ ${ }^{I}$ (Department of Anatomy, Kempegowda Institute of Medical Sciences, Bangalore, India) \\ ${ }^{2}$ (Department ofAnatomy, International Medical School, Bangalore, India)
}

\begin{abstract}
Endocrine causes of male infertility are often referred as pretesticular causes. Impairment of fertility in these cases is secondary to either a hormone deficiency or an excess. Pubertal testicular failure or castration results in the persistence of sexual infantilism.Present study has been attempted on consecutivelyreferred 119 male patients with sexual infantilism and infertility to Division of Human Genetics (DHG), Department of Anatomy, St. John's Medical College (SJMC), Bangalore, for cytogenetic investigations and counseling .In the present study Among the 44 probands, with Hypogonadism which8(40\%) of them showed increase in LH and $4(20 \%)$ decrease.Out of 22 probands with FSH,12(54.5\%) had increase and 5(22.7\%) decrease in FSH. Out of 27 probands with testosterone, 1(3.7\%) of them had shown increase and 21(77.7\%) decrease in testosterone. Among the 75 probands with infertility, 12 had undergone LH of which 3(25\%) of them had increase and 1(8.3\%) decrease in LH. Out of 15 probands with FSH, 6(40\%) had increase and1(6.6\%) decrease in FSH. out of 9 probands with testosterone $1(11.1 \%)$ had shown increase and $5(55.5 \%)$ decrease. Out of 10 probands with prolactin 3(30\%) of them showed increase in prolactin, none of them showed decrease and $7(70 \%)$ of them were normal. In the present study among 12 patients with 47,XXY karyotype, elevated levels of LH was noted in 7(87.5\%), and 8(88.8\%) in FSH and one (11.1\%) in testosterone levels. Decreased levels of testosterone was observed among 7(77.7\%). In the present study 2 probands with 46,XY /47,XXYmosaicism, 1(50\%)showed increase in LH and 1(50\%)in FSH and both the patients 2(100\%) decrease in testosterone. This studyhighlights hormonal factor as one of the etiology that may adversely affect male reproduction in probands with infertility and hypogonadism and indicates that the measurements of FSH,LH and testosterone are useful tests in the management of male infertility.
\end{abstract}

Keywords: Chromosomal abnormality, Follicle stimulating hormone, Klinefelter Syndrome, Luteinising hormone, Testosterone

\section{Introduction}

Normal male, sexual and reproductive functions depend on an intact hypothalamic pituitary gonadal axis to maintain a normal hormonal milieu. Although male reproductive function is critically dependent on endocrinologic control, less than 3\% of infertile men have a primary hormonal etiology. The most common abnormality detected on routine testing of infertile men is elevated serum Follicle stimulating hormone (FSH). An elevated FSH level is indicative of significant problem with spermatogenesis. Primary gonadal failure and impaired secretion of gonadal steroids lead to decreased negative feed back and elevated Luteinising hormone (LH) and FSH levels. FSH and LH bind to the receptors and regulate testicular function by promoting sex steroid production and gametogenesis. The hypothalamus synthesizes gonadotrophin releasing hormone $(\mathrm{GnRH})$ stimulate the pituitary to secrete both FSH and LH. These gonadotropin hormones inturn influence leydig-cell function and spermatogenesis. FSH stimulates the development of testosterone receptors, Androgen binding protein(ABP) produced by sertoli cells may modulate the action of LH on leydig cells. Circulating concentration of testosterone and estradiol controls secretion of LH. FSH exerts its action on sperm production by affecting an increased output of spermatozoa. The failure of pituitary to secrete FSH and LH will result in disruption of testicular function in infertility. The two androgens responsible for all aspects of male sexual differentiation are testosterone and Dihydrotestosterone. Testosterone is produced by Leydig-cells which act upon sertoli and peritubular cells of seminiferous tubules and initiates spermatogenesis. To maintain spermatogenesis higher intratesticular levels of testosterone are required.[82,133,134].

The most common forms of primary gonadal failure are associated with sex chromosomal abnormalities and characteristic physical findings namely KFS and its variants (Kulin 1989, Landau 1989, Grumbach\&Styne 1992,Sigman\&Jarow 2003, Grumbach et al 2003).

\section{Materials and Methods}

The study has been done on consecutively referred one hundred and nineteenmale patients withhypogonadismand infertility referred to division of Human Genetics, department of anatomy St.John's medical college, Bangalore, India. The reasons for referral were male probands with primary and secondary 
infertility and hypogonadismwith absence of primary or secondary sexual characters. Cytogenetic investigation was done to detect any chromosomal abnormality.Cytogenetic investigations include modified leucocyte microculture method, GTG banding technique, photography and karyotyping.Hormonalprofile were gathered from the proforma and the data was analysed. At the time of referral, patients consent has been duly obtained.

\section{Results:}

Out of 119 probands, 44 presented with hypogonadism and75 withinfertility,the hormonal measurements for FSH,LH,Testosterone and Prolactin has been gatheredfrom the proforma and percentage has been shown in tables (1-4). The hormonal assay was not available for all the probands, Thus from the available data, the results have been interpreted.

Inference(Table-1)Among the 44 probands with Hypogonadism, 20 had undergone LH, of which $8(40 \%)$ of them had increase and $4(20 \%)$ decrease in LH. Out of 22 probands with FSH 12(54.5\%), had increase and $5(22.7 \%)$ decrease in FSH.Out of 27 probands with testosterone, 1(3.7\%)of them had shown increase and $21(77.7 \%)$ decrease in testosterone. Out of 15 probands with prolactin, $2(13.3 \%)$ of them showed increase in prolactin, $1(6.6 \%)$ decrease in prolactin.

Inference (Table-2) Among the 75 probands with infertility, 12 had undergone LH of which 3(25\%) of them had increase and $1(8.3 \%)$ decrease in LH. Out of 15 probands with FSH 6( 40\%) had increase, 1(6.6\%) decrease in FSH.. out of 9 probands with testosterone 1(11.1\%) had shown increase and 5(55.5\%) decrease. Out of 10 probands with prolactin $3(30 \%)$ of them showed increase in prolactin, none of them showed decrease and 7 ( $70 \%$ )of them were normal.

Inference(Table-3) Among 44 probands with hypogonadism, 12 presented with 47,XXY karyotype, 7(87.5\%) showed increase in LH and $8(88.8 \%)$ in FSH and one (11.1\%)in testosterone levels. Decreased levels of testosterone was observed among 7(77.7\%).Among the 2/2 probandswith 46,XY /47,XXYmosaicism, $1(50 \%)$ showed increase in $\mathrm{LH}$ and $1(50 \%)$ in FSH and both the probands2 $(100 \%)$ decrease in testosterone.

Inference(Table-4): Among 75 probands with infertility, the 8/12 probandspresented with 47,XXY karyotype, $7(87.5 \%)$ showed increase in LH and $8(88.8 \%)$ in FSH and one (11.1\%)in testosterone levels. Decreased levels of testosterone was observed among $7(77.7 \%)$.Among the 2/2 probandswith 46,XY /47,XXYmosaicism, $1(50 \%)$ showed increase in LH and 1(50\%)in FSH and both theprobands 2(100\%) decrease in testosterone.

\section{Discussion}

Male hypogonadism encompasses the somatic and functional consequences of a deficiency of male hormone as well as reproductive inadequacy or failure. In primary testicular failure the testes fail to develop normally or damaged by intercurrent disease, injury or medical manipulation. Hypogonadism is characterised by a low testosterone level and may be primarily associated with high gonadotropin levels. Secondary hypogonadism may be congenital or acquired. Congenital hypogonadism may be due to failure of migration of hypothalamic neuroendocrine cells, associated with other midline defects such as cleft palate, anosmia, cryptorchidism, microphallus and delayed puberty[34].

In secondary testicular failure or Hypogonadotropichypogonadism $(\mathrm{HH})$ partial or complete testicular failure is a consequence of pituitary gonadotrophin deficiency. Elevated serum FSH and LH values help to distinguish from(hypergonadotropichypogonadism) from secondary testicular failure. Hypogonadotropichypogonadism may result from developmental or acquired pituitary disease or a primary failure of secretion of the hypothalamic gonadotropic releasing hormone(GnRH). There also hypogonadal syndromes. These syndromes are explained by a genetic deficiency in specific enzymes responsible for hormone synthesis, the secretion of defective hormone or tissue hormone receptor failure[ 41]. Pubertal testicular failure or castration results in the persistence of sexual infantilism. A low serum testosterone level is one of the best indicators of hypogonadism of hypothalamic or pituitary origin. Mean serum LH and FSH concentration are significantly low in hypogonadotropichypogonadism. If it occurs before puberty signs of eunuchoidism, decreased hair and muscular development and infantile genitalia may be observed.Acquired forms of hypogonadotropichypogonadism occurs in patients with normal pubertal development with a recent history of decreased sexual function and fertility. Partial defect in gonadotropin secretion (lowLH and normal FSH) Low levels leads to fertile Eunuch syndrome.Elevated FSH and LH values help to distinguish primary testicular failure from secondary testicular failure. Low levels of FSH, LH and testosterone suggest acquired hypogonadotropichypogonadism. Eunuchoid habits with infantile genitalia,sparse body hair, gynecomastia, low testicular volume are seen in congenital gonadotropin deficiency[52]. Hypothalmic pituitary gonadal axis may be adversely affected either by tumors example pituitary adenoma which can produce hypogonadism and infertility.Atropic testes, abnormal hair distribution and increased facial wrinkilingare all clinical signs of hypogonadism. Ejaculate volumes also be reduced in patients with hypogonadism.[38]. 
In the present study (Table1)Among the 44 probands, with Hypogonadism 20 had undergone LH, of which $8(40 \%)$ of them had increase and $4(20 \%)$ decrease in LH. Out of 22 probands with FSH, 12(54.5\%) had increase and $5(22.7 \%)$ decrease in FSH.Out of 27 probands with testosterone, 1(3.7\%)of them had shown increase and $21(77.7 \%)$ decrease in testosterone.Out of 15 probands with prolactin, $2(13.3 \%)$ of them showed increase in prolactin, $1(6.6 \%)$ decrease.

The incidence of endocrine abnormalities in an infertile population ranges from 2 to $9 \%[122]$. The failure of pituitary to secrete FSH and LH will result in disruption of testicular function and infertility, germcell arrest, sertoli cell only syndrome, seminiferous tubule hyalinization[32,136]. Studies have shown that Leydigcell function may be altered in men with germinal epithelial injury resulting in selective increase in FSH concentration. LH secreted by Leydig-cell is the major modulator of testosterone [82].Testosterone is the major physiological inhibitor of both FSH and LH and its deficiency results in the virilisation of male sex differentiation. In men presenting with infertility,gonadotrophin deficiency accounts for less than $5 \%$ of the causative factors. FSH is considered as a reliable indicator of germinal epithelial damage and found consistently elevated in sertoli cell only syndrome and also elevated serum FSH levels were found most frequently in association with severe testicular damage. The gonadotrophins, FSH and LH are significantly elevated in infertile group especially in the azoospermic men with low testicular scores[135,136].

Elevated mean serum FSH and LH levels has been reported in infertile men with varicocele[3].Several authors have suggested that elevated serum FSH concentration in men with azoospermia or with oligospermia indicate severe hypospermatogenesis.Hyperprolactinaemia has been reported to cause oligospermia, but diagnostic value of routine prolactin measurements is extremely low in men with semen abnormalities, unless associated with decreased libido, impotence and evidence of hypogonadism. Excessive serum prolactin levels cause both reproductive and sexual dysfunction. Mild elevations of prolactin $(<50 \mathrm{ng} / \mathrm{ml})$ have been more frequently noted in infertile men[42].Elevated levels of FSH and LH in infertile males have been reported[13,27]. The mean FSH and LH were significantly elevated in both azoospermic, oligozoospermic infertile males. Normal levels of testosterone have been reported in infertile males[71]. In adults FSH and LH levels are elevated and testosterone is usually below normal or in the lowerpart of the normal range, elevations in plasma FSH and LH levels reflect deficient testicular function and consequent lack of feed back inhibition by sex steroids and inhibin on pituitary and hypothalamus.

In the present study(Table 2),gonadotropin [FSF \&LH] were significantly elevated in infertile males. Among the 75 probands, 12 had undergone LH of which $3(25 \%)$ of them had increase and $1(8.3 \%)$ decrease in LH. Out of 15 probands with FSH, 6(40\%) had increase and1(6.6\%) decrease in FSH. out of 9 probands with testosterone $1(11.1 \%)$ had shown increase and $5(55.5 \%)$ decrease. Out of 10 probands with prolactin $3(30 \%)$ of them showed increase in prolactin, none of them showed decrease and $7(70 \%)$ of them were normal.

Hormonal /Chromosomal abnormality:KFS is the most common cause of hypogonadism in males. Prepubertally the plasma concentration of follicle stimulating hormone and luteinising hormone responds to luteinising hormone releasing factor within normal range[24]. Another study also has reported prepubertal 47,XXY boys show no significant abnormalities in gonadotropin or testosterone serum levels[23].In adults FSH and LH levels are elevated and testosterone is usually below normal or in lower part of the normal range. Elevations in plasma FSH and LH levels reflect defiecient testicular function and consequent lack of feed back inhibition by sex steroids and inhibin on pituitary and hypothalamus[23].LH, FSH and testosterone are prime regulators of germ cell development and quantitative production of spermatozoa. As reported in the literature FSH is most important for spermatogenesis. Damage to seminiferous tubule, germinal, sertoli cell only syndrome and Klinefelter syndrome are associated with elevated levels of FSH. Hormonal serum levels are reduced in $80 \%$ cases of KFS and FSH and LH usually are above normal levels. FSH may be highly increased[13]. Among the 44 probands with hypogonadism, in the present study (Table3,4)(Fig.1) 12 patients presented with 47,XXY karyotype, elevated levels of LH was observed in, 7(87.5\%), and 8(88.8\%) in FSHand one (11.1\%)in testosterone levels. Decreased levels of testosterone was observed among 7(77.7\%). Among 75 with infertility 4 patients presented with 47,XXY karyotype 1(25\%) showed increase in LH and 2(50\%) in FSH. Decreased Levels of testosterone was observed among 2(50\%).

Mosaic KFS- Endocrine abnormalities occur in patients with mosaic KFS. In general these patients manifest a lesser degree of gynaecomastia, androgen deficiency and testicular pathology, Secondary sexual characteristics are less impact than those of patients with 47,XXY karyotype. The manifestations of the mosaic form are usually less severe than with 47,XXY variety and the testes may be normal in size[23].In the present study (Table 3,4) (Fig.2) 2 probands withhypogonadism presented with 46,XY /47,XXYmosaicism, $1(50 \%)$ showed increase in LH and 1(50\%)in FSH and both the patients $2(100 \%)$ decrease in testosterone.3probands with infertility showed 46,XY/47,XXY mosaicism 1(33.3\%) showed decrease in LH and $1(33.3 \%)$ in FSH and 1(33.3\%) decrease in testosterone. Prolactin increase was observed in 1(33.3\%). 


\section{Conclusion:}

Gonadal causes of infertility constitute largest group of disorders. Mutations affecting gonadal function include gonadotropin receptors, steroid hormone receptors, steroid synthesis defects as well as miscellaneous causes. Thus the present study reports hormonal factors and in the counseling sessions the probands were advised for hormonal therapy. Any mutations of the genes involved in the primary sexual determination could have manifested in hypogonadism and infertility. Molecular studies may establish to diagnose precisely the genes involved in mutations.

\section{References:}

[1] Steinberger E. The thyroid gland in male infertility.Current therapy of infertility.Trenton,B.C.DeckerInc.New Jersey;1982-1983.

[2] Lincoln GA. "Pituitary control of testis", British medical bulletin; 1979;35: 167-172.

[3] UrryRL.Pathophysiologic principles of male infertility. Urologic clinics of North America. 1984;8:3-15.

[4] Jarow JP. Life threatening conditions associated with male infertility. Urologic clinics of North America;1994: 21:409-415

[5] Landau RL. Endocrionology. Philadelphia. Saunders;1989.

[6] Goswami D, KriplaniA.Current concepts in male factor infertility and its management. Asian journal of Obs and Gynae practice;2000;4:10-15.

[7] 1McClureRD.Office evaluation of the infertile man. New York. Springer Verlag;1997.

[8] Caldamone A, Valve JR, Cockett ATK. Evaluation of the infertile or subfertile male.Urologic clinics of North America.1982;3:339341 .

[9] Griffin JE, Wilson JD. Williams text book of Endocrionology.USA: Saunders;2003.

[10] De Kretser DM. Endocrionology of male infertility.British Medical Bulletin.1979; 35: 187-192.

[11] De Kretser DM, Burger HG, Hudson B.The relationship between germinal cells and serum FSH levels in males with infertility.JCE\&M 1974; 38:787-793.

[12] BelseyMA. The epidemiology of infertility: a review with particular reference to Sub-Saharan Africa. Bulletin World Health Organ 1976;54:319-340.

[13] Sigman M, Jarow JP. Campbell's urology, USA. Saunders;2002.

[14] Nieschlag E. Male Reproductive Health and Dysfunction. New York. Springer Verlag;1997.

[15] Abramsson L, Beckman G, Duche KM, Nordenson I. Chromosomal aberrations and male infertility. The journal of Urology;1982;128:52-53

[16] Micic M, Mimic S, Babic M, Diklic V. Phenotype of two males with abnormal Y chromosomes. Clinical Genetics.1990; 37: 321326.

[17] Simpson,Elias. Genetic aspects of Gynaecological Disorders Edition. USA: Saunders;2003.

[18] Grumbach MM, Hughes LA and Conte FA. Williams text book of Endocrionology, USA; Saunders;2003.

\section{Tables}

Table1:Hormonal profile/Hypogonadism(n-44)

\begin{tabular}{|l|l|l|l|l|}
\hline Hormones & Increased & Decreased & Normal & Not done \\
\hline LH(n-20) & 8 & 4 & 8 & 24 \\
\hline FSH(n-22) & 12 & 5 & 5 & 22 \\
\hline Testosterone(n-27) & 1 & 21 & 5 & 17 \\
\hline PRL(n-15) & 2 & 1 & 12 & 29 \\
\hline
\end{tabular}

LH- Luteinising hormone, FSH- Follicle stimulating hormone, PRL- Prolactin

Table 2:Hormonal profile/Infertility(n-75)

\begin{tabular}{|l|l|l|l|l|}
\hline Hormones & Increased & Decreased & Normal & Not done \\
\hline LH(n-12) & 3 & 1 & 8 & 63 \\
\hline FSH(n-15) & 6 & 1 & 8 & 60 \\
\hline Testosterone(n-9) & 1 & 5 & 3 & 66 \\
\hline PRL(n-10) & 3 & - & 7 & 65 \\
\hline
\end{tabular}

Table 3: Hormonal profile/Hypogonadism/Chromosomal Abnormality

\begin{tabular}{|l|l|l|}
\hline Hormone & $47, \mathrm{XXY}(\mathrm{n}-12)$ & $46, \mathrm{XY} / 47, \mathrm{XXY}(\mathrm{n}-2)$ \\
\hline $\begin{array}{l}\text { LH }(8) \\
\text { I }\end{array}$ & 7 & 1 \\
\hline D & - & - \\
\hline Nor & 1 & - \\
\hline Not done & 4 & \\
\hline $\begin{array}{l}\text { FSH(9) } \\
\text { I }\end{array}$ & 8 & 1 \\
\hline D & - & - \\
\hline Nor & 1 & - \\
\hline Not done & 3 & \\
\hline $\begin{array}{l}\text { Testosterone(9) } \\
\text { I }\end{array}$ & 1 & - \\
\hline D & 7 & 2 \\
\hline Nor & 1 & 1 \\
\hline Not done & 3 & \\
\hline PRL(5) & - & - \\
\hline
\end{tabular}




\begin{tabular}{|l|l|l|}
\hline I & & \\
\hline D & - & - \\
\hline Nor(12) & 5 & 1 \\
\hline Not done & 7 & \\
\hline
\end{tabular}

I-Increase, D-Decrease, Nor-Normal,

Table 4:Hormonal profile/Infertility/Chromosomal abnormality(n-75)

\begin{tabular}{|l|l|l|}
\hline Hormone & $47, \mathrm{XXY}(\mathrm{n}-4)$ & $46, \mathrm{XY} / 47, \mathrm{XXY}(\mathrm{n}-3)$ \\
\hline $\begin{array}{l}\text { LH } \\
\text { I }\end{array}$ & 1 & - \\
\hline D & - & 1 \\
\hline Nor & 1 & - \\
\hline $\begin{array}{l}\text { FSH } \\
\text { I }\end{array}$ & 2 & - \\
\hline D & - & 1 \\
\hline Nor & - & - \\
\hline $\begin{array}{l}\text { Testosterone } \\
\text { I }\end{array}$ & - & - \\
\hline D & 2 & 1 \\
\hline Nor & 1 & - \\
\hline $\begin{array}{l}\text { Prolactin } \\
\text { I }\end{array}$ & - & 1 \\
\hline D & - & - \\
\hline Nor & 1 & 1 \\
\hline
\end{tabular}

\section{Figures}

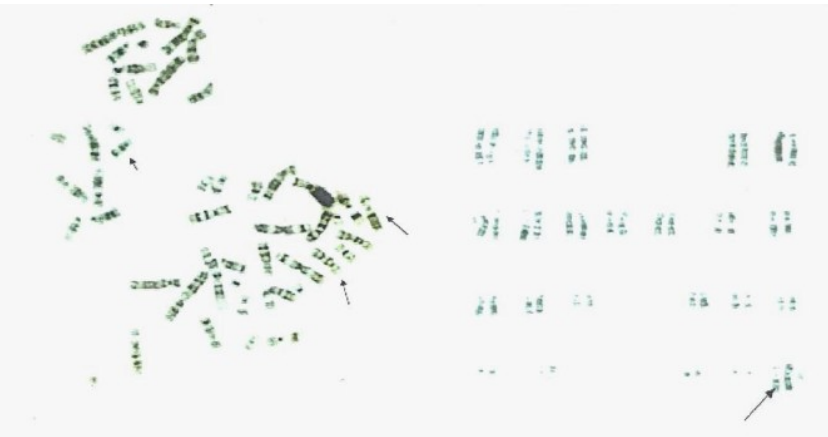

Figure1:GTG banded metaphase spread and karyotype:47,XXY. Arrows indicate XXY chromosomes in the metaphase spread

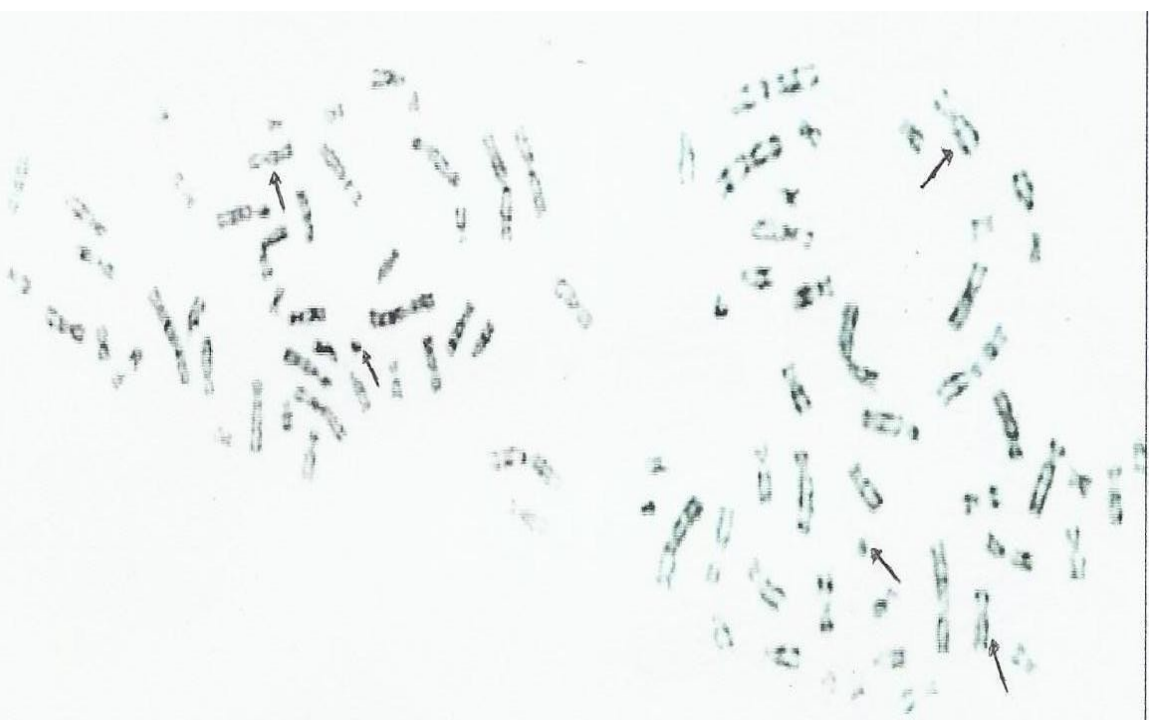

Figure2:GTG banded metaphase spread 46,XY/47,XXY. Arrows indicate XYand XXY chromosomes in the metaphase spread 